\title{
Focal retrograde amnesia and the episodic-semantic distinction
}

\author{
MARK A. WHEELER and COREY T. MCMILLAN \\ Temple University, Philadelphia, Pennsylvania
}

\begin{abstract}
This article reports a review of focal retrograde amnesia (FRA), or the phenomenon of organically based severe memory loss restricted to retrograde, or pretraumatic, memory. Cases of FRA are classified according to the type of memory loss: episodic, semantic, or both. A few different clusters of the disorder were identified. Lesions to either the anterior temporal lobes or the posterior/visual cortex can result in an FRA that devastates retrograde episodic memory, while having smaller effects on semantic memory. A number of left-hemisphere patients have FRA confined to semantic memory. There are several additional examples of FRA following minor cerebral trauma that disrupts either episodic memory alone or both episodic and semantic memory that are not accompanied by evidence of structural brain lesions. We discuss these different profiles of FRA and their implications for the understanding of memory retrieval.
\end{abstract}

Although there are many different varieties of amnesia, it is the study of anterograde amnesia that has dominated neurocognitive research into memory disorders. It is now well known that damage to the hippocampal system or the diencephalon will drastically impair the ability to consciously retain newly encountered information. Yet, a number of patients with amnesia have little or no difficulty in the acquisition of new material.

Patients suffering from focal retrograde amnesia (FRA) are unable to consciously report information that was encoded in a normal fashion prior to the onset of pathology, despite the ability to encode, store, and retrieve posttraumatic episodes and facts. In one example, a 30-year-old female developed FRA following a closed-head injury (Kapur, Ellison, Smith, McLellan, \& Burrows, 1992), sustaining damage to the temporal poles bilaterally. Despite extensive cuing, the patient was unable to recollect any previous events from her life, including events that should have been highly salient, such as recent holidays and the funeral of one of her grandmothers. She had similarly lost almost all knowledge of news events and famous people that had been prominent in the media. Because of her anterograde abilities, the woman was able to quickly reacquire many facts about the world and also about her autobiography. Yet even after such relearning, memory for pretraumatic facts and episodes could not be considered normal. She could not recollect any pretraumatic happenings in the personal, subjective way that characterizes retrieval from episodic memory. Instead, the woman learned to recite the incidents of her early life, much as a student might acquire the skill of reciting the biography of a famous person.

Correspondence concerning this article should be addressed to M. A. Wheeler, Department of Psychology, Weiss Hall, Temple University, Philadelphia, PA 19122 (e-mail: mwheeler@nimbus.temple.edu).
Because anterograde memory is often normal or nearly normal, it is not surprising that most patients with FRA do not have massive pathology in the medial temporal cortices. But the neural correlates of this phenomenon remain relatively poorly understood. For example, O' Connor, Butters, Miliotis, Eslinger, \& Cermak (1992) described a young woman who developed a memory profile very similar to that in Kapur et al. (1992) following an episode of encephalitis. Yet the two cases were different in some other ways. Unlike the previous patient, her lesion was limited almost exclusively to the right side and extended throughout the posterior temporal, parietal, and occipital cortices. Also, there was a coexisting disruption in visuospatial processing, and the authors suggested that the visuospatial deficits were probably contributing to the retrograde amnesia.

An understanding of FRA is important for a number of reasons. First, the phenomenon represents a dissociation between encoding and storage/retrieval mechanisms, with the first of these being relatively spared and the latter mechanisms being clearly impaired. It may be the case that FRA results from the destruction of the neural correlates of the memory traces themselves, making the traces unavailable, even when strong cues are present. Another possibility is that affected patients are unable to integrate the different fragments of a stored experience. Complex retrieval from long-term memory often requires an individual to establish a retrieval mode (Nyberg et al., 1995) that initiates, guides, and monitors the neurocognitiveretrieval processes. The inability to form an appropriate model for retrieval can render entire classes of previously retrievable information inaccessible. Such an explanation implies that the retrieval of posttraumatic experiences must be mediated by neural networks outside of those that have been injured or disrupted.

An understanding of FRA can also help to support or constrain ideas about the fractionation of human memory. Theories about multiple memory systems depend on dis- 
sociations, or the findings that some variables (such as brain injuries) affect one class of memory tests differently than other classes of tests. It is through the findings of dissociations that one can justify proposing different varieties of memory. Individual case studies have shown dissociations within retrograde amnesia. For example, a patient reported by Hodges and McCarthy (1993) was profoundly impaired when he attempted to report knowledge about famous events, yet showed good knowledge for famous people. Of course, the finding of a dissociation in one patient between pretraumatic memory for people and events does not imply the existence of separable memory systems for these two types of information. It does, however, support the idea that the neurocognitive storage and retrieval of people and events depends on neurocognitive processes or structures that are at least partly distinct from one another. Evidence from FRA should ultimately play a valuable role in distinguishing between the different neural representations underlying different kinds of memory retrieval.

The investigation of FRA is especially relevant for the distinction between episodic and semantic memory. Episodic memory makes possible the recollection of personally experienced events as they were originally experienced; it is through the episodic memory system that individuals can remember their past. Semantic memory handles factual information, and retrieval from semantic memory allows individuals to know things about the world. Extensive discussions about the proposed similarities and differences between these two varieties of memory can be found elsewhere (Tulving, 1983; Wheeler, Stuss, \& Tulving, 1997).

Although the terms episodic and semantic memory have become securely assimilated into the language of cognitive neuroscience, there is still disagreement over the proper way to think about the two kinds of memory. Some have claimed that any differences between episodic remembering and semantic knowing are relatively minor and that there is little reason to postulate separate neurological bases (Glenberg, 1997; McClelland, McNaughton, \& O'Reilly, 1995). Others see the distinction as critical and important and have tried to uncover the neural correlates and processes that are specific to each hypothetical system (Dalla Barba, Parlato, Jobert, Samson, \& Pappata, 1998; Tulving \& Markowitsch, 1998).

A few notable case studies describe patients with syndromes that appear to honor the episodic-semantic distinction. A recent case study (Levine et al., 1998) described a man who became amnesic for pretraumatic events following a closed-head injury. The patient was unable to episodically recollect any moments about his life prior to the injury. Yet it was not the case that he did not know anything about himself. He was able to report many autobiographical facts about himself, such as the names of his teachers and friends from early childhood, the dates of his high school graduation and wedding, and the destinations of many of his previous vacations. These reports appeared to be retrieved via semantic memory, however, since they were not accompanied by any sense of mentally reliving past experiences.

A different case involved an Italian student who suffered a closed-head injury and was diagnosed with an injury to the left parietal cortex (Grossi, Trojano, Grasso, \& Orsini, 1988). Upon resuming her studies, she realized that she could not recall much of the factual information that had been acquired prior to her injury. She did not know who either Cicerone [Cicero] or Michelangelo was, and she had forgotten the names of many major Italian cities. The patient's retrograde amnesia did not extend to episodic recollections, however, resulting in some unusual profiles on memory tasks. For example, she could not recall anything about the subject of pedagogy, or even define the term, although this had been one of her best subjects prior to her injury. Yet the patient could episodically recollect several meetings with her pedagogy teacher and even provide contextual details about those meetings. In this and other anecdotes, there was a sharp dissociation for pretraumatic semantic knowledge, which was profoundly impaired, and episodic recollections, which were apparently normal. Symptoms represent a reversal of the phenomenon of source amnesia (Schacter, Harbluk, \& McLachlan, 1984). The patient could not recall many of the semantic contents of prior learning experiences, yet could recollect many of the actual experiences of learning.

Taken together, these case studies comprise a double dissociation between episodic and semantic memory in retrograde amnesia. Neither patient exhibited symptoms that could be more easily explained by the difficulty or salience of the requested information. For example, the individual described by Levine et al. (1998) could acknowledge a few facts about some pretraumatic events that were very emotional to him at the time (e.g., a friend's death), yet could not recollect his reactions at the time. The memories lacked the emotional, temporal, and spatial details that characterize most examples of episodic recollection. Conversely, the young woman studied by Grossi et al. (1988) could not retrieve the names of European capitals or the locations of the continents, although she was unimpaired as she recollected episodic details from her distant past, back to her earliest years in school. The existence of these, and similar, cases supports the hypothesis that episodic and semantic information must be represented in at least partly dissociable ways in the human brain.

In a recent paper, Kapur (1999) critically reviewed a wide range of memory disorders that include components of retrograde memory loss. The disorders included FRA, as well as retrograde amnesias accompanying other neurological syndromes, such as semantic dementia, transient global amnesia, and hippocampally based anterograde amnesia. Also discussed were cases of retrograde loss following electroconvulsive therapy and closed-head injuries. Kapur drew a number of conclusions that are relevant to the relation between FRA and the episodicsemantic distinction. First, he confirmed the distinction 
between the temporally limited retrograde amnesias that commonly accompany injuries to the limbic-diencephalic areas and the extensive episodic or semantic retrograde amnesias that occasionally result from neocortical injuries. Whereas most cases of retrograde amnesia belong to the former classification, the majority of FRA cases are contained within the latter group. Perhaps more important, Kapur concluded that the loss of semantic memory is often dissociable from the loss of episodic memory in FRA. Across several studies, there appeared to be a selective loss of one of these hypothetical systems of memory, combined with at least a relative sparing of the other. In some other case studies, however, there was no evidence for such a dissociation.

The review paper (Kapur, 1999) serves as a good foundation for further exploration into the status of episodic and semantic memory in FRA. Although there now exist several examples implicating either episodic remembering or semantic knowing, there are a number of issues that remain unresolved. One issue stems from the considerable variability across different case studies. Some affected patients demonstrate a temporal gradient, so that older pretraumatic memories are more likely to be spared than recent ones (Fujii, Yamadori, Endo, Suzuki, \& Fukatsu, 1999; Klein, Loftus, \& Kihlstrom, 1996; Reinvang \& Gjerstad, 1998; Stracciari, Ghidoni, Guarino, Poletti, \& Pazzaglia, 1994). Yet in most cases, the amnesia extends throughout all life periods; many patients with FRA cannot recollect even a single event that they participated in before the onset of amnesia. Similarly, as was mentioned before, although a number of patients show sharp dissociations between semantic and episodic retrograde memory, there are several others demonstrating seemingly equivalent impairments in the two systems (e.g., Carlesimo, Sabbadini, Loasses, \& Caltagirone, 1998; De Renzi \& Lucchelli, 1993; Reinvang \& Gjerstad, 1998).

There is also much variability with respect to the lesion location. Kapur (1999) noted that "extensive episodic or semantic retrograde amnesia generally entails lesions to a wide range of neocortical structures, particularly those in the temporal lobe" (p. 819). Although undoubtedly true, such localization is not very precise, and some patients have injuries that are confined within the occipital and parietal lobes (see, e.g., Hunkin et al., 1995; Ogden, 1993). In other cases, structural imaging has failed to uncover evidence of any underlying brain lesion (e.g., Maravita, Spadoni, Mazzucchi, \& Parma, 1995; Yoneda, Yamadori, Mori, \& Yamashita, 1992).

Because the symptoms and lesion locations often vary from patient to patient, it is still unclear whether FRA represents a single phenomenon or whether more meaningful subcategories of the disorder should be distinguished. Given the existing state of knowledge, it is also difficult to associate remote episodic and semantic retrieval with particular brain regions or networks. The neural correlates of episodic and semantic memory are central topics in cognitive neuroscience, and it is sur- prising and perhaps disappointing that relatively little is known about these issues.

\section{EMPIRICAL REVIEW}

The goal of this review is to further explore the phenomenon of FRA, especially as it relates to episodic and semantic memory. We used the episodic-semantic distinction as an organizing tool for classifying the published case studies of FRA. Such a classification allows for the investigation of a number of different issues, such as (1) the relative frequency of different types of FRA, those disrupting episodic memory, semantic memory, or both; (2) the presence or absence of temporal gradients associated with episodic and semantic memory loss; and (3) the location of the neuropathology accompanying the different classes of FRA. This last issue is probably the most important. The failure to find different patterns of brain injuries underlying episodic and semantic retrograde amnesia would cast doubt on the proposal that these two varieties of memory are differently represented in the brain. By contrast, the discovery that episodic and semantic FRA have distinct neural profiles would provide important information about differences between the two systems.

\section{Method}

Flagging of articles. Articles were flagged through a computerized search through the MEDLINE and PsycINFO databases. Articles were selected if their titles, keywords, or abstracts mentioned "retrograde amnesia." The search was limited to articles published in English since 1985 that involved adult human subjects. Although there were some published cases of FRA prior to 1985 (Goldberg et al., 1981; Roman-Campos, Poser, \& Wood, 1980; Williams \& Smith, 1954), these reports appeared before the episodic-semantic distinction was popularized (Tulving, 1983, 1984), and the authors did not give formal episodic and semantic tests to their patients. Also, given that structural neuroimaging has dramatically improved in recent years, it seemed reasonable to limit the search to the last 15 years. We examined all flagged articles for references to other relevant case reports. Especially helpful were a few recent papers (Fujii et al., 1999; Kapur, 1999; Rubin \& Greenberg, 1998).

Selection criteria. To be included in the review, a case had to meet several criteria. First, the patient must be unable to know and/or remember pretraumatic information that had previously been retrievable. In most cases, these symptoms were obvious to both the patients and their families. Following the lead of Kapur (1999) and others, we distinguish FRAs from other disorders that involve more general losses in the ability to neurally represent and become consciously aware of some specific category of information. These distinctions are especially important in the case of semantic memory. For example, syndromes such as aphasia and visual agnosia may prevent patients from recognizing or knowing things that they had 
learned previously. Such cases can be classified as semantic memory disorders, but by themselves, these symptoms do not qualify as amnesias, and affected patients do not have intact anterograde learning abilities for semantic information. Further support for the distinction between semantic amnesia and other semantic disorders comes from the patients themselves - most of the individuals with purely semantic FRA discovered for this review showed no aphasic disturbances (Grossi et al., 1988; Markowitsch, Calabrese, Neufeld, Gehlen, \& Durwen, 1999; Yasuda, Watanabe, \& Ono, 1997).

Second, we excluded patients with profound disorders of anterograde memory. Application of this criterion was not always straightforward, because a number of the patients, especially those that had suffered closed-head injuries, were mildly impaired at new learning. Our decision as to whether to include a patient was typically settled by examining the ability to relearn whatever information was lost. For example, a young woman studied by De Renzi, Liotti, and Nichelli (1987) suffered a severe retrograde amnesia for semantic knowledge and also showed considerable impairments on neuropsychological tests of anterograde memory. Yet she was also able to relearn the facts about the world and her life that had been lost during her trauma, and we therefore included this patient in the review. For each case that was included, there was a compelling asymmetry between retrograde memory (massively impaired) and anterograde memory (less impaired).

All of the patients must have sustained some brain or head injury. In other words, we wanted to rule out cases of psychogenic, or psychologically based, amnesia. The profile of a patient with psychogenic amnesia strongly resembles that of FRA. There is often a complete loss of both episodic and semantic retrograde memories, especially for information important for self-identity (Kihlstrom \& Schacter, 1995; Kopelman, 1987). The process of discriminating between organic and psychogenic retrograde amnesia is far from simple, and there are no definitive rules that allow a retrograde amnesia to be classified as one or the other, although some guidelines have been suggested (Kapur, 1999). It is also possible that both types of retrograde amnesia may occasionally appear together in the same patient (see Stuss \& Guzman, 1988). For this review, we selected a few conditions that were necessary for a diagnosis of organic, as opposed to psychogenic, amnesia. The symptoms must have appeared following some accident or neurological illness. There must not have been a history of psychiatric illness or drug abuse. Also, there could be no evidence of malingering and no motivation for intentionally exaggerating the extent of the syndrome. Note that patients were not excluded from the study simply because structural neuroimaging failed to discover the presence of any organic injury. It may commonly be the case that physical injuries are too subtle to be detected by standard imaging. We have included several cases in which patients, all following closed-head injury, presented the profile of FRA despite a seemingly nonremarkable neuroimage (De
Renzi, Lucchelli, Muggia, \& Spinnler, 1997; Klein et al., 1996; Lucchelli, Muggia, \& Spinnler, 1995; Maravita et al., 1995; Stracciari et al., 1994).

Variables summarized in this review. For each relevant case, the following information was extracted: (1) authors and year of publication; (2) the lesion etiology (usually either closed-head injury or encephalitis); (3) the location of the brain lesion, as discovered by structural neuroimaging; (4) performance on different tests of pretraumatic episodic memory (described in detail in the next section); and (5) performance on tests of pretraumatic semantic memory (described in the next section).

Tests of episodic and semantic retrograde memory. It is more difficult to test retrograde than anterograde memory functioning. Whereas it is relatively straightforward to present subjects with to-be-remembered information and later measure their ability to recall or recognize the target material, assessments of retrograde memory ability necessarily assess the retention of information that was acquired outside of an experimental setting. Thus, it is sometimes difficult to know just what the appropriate test questions should be and whether or not a patient's pretraumatic memory is accurate. For these and other reasons, Kapur (1999) has noted that there are fewer standard retrograde than anterograde tests of memory. Given the lack of precision that is inherent in such measurement, it is critical for researchers to use as many converging measures of retrograde memory as possible and also to assess the consistency between test performance and patients' difficulties in everyday life.

Pretraumatic memory has been probed using a semistructured Autobiographical Memory Interview (AMI). In the procedure (Kopelman, Wilson, \& Baddeley, 1990), subjects answer specific questions that cover different life periods, including childhood and early adulthood. In the episodic part of the interview, the subjects are asked to recollect specific events to probes, such as "your wedding day" and "your first-grade classroom," and to include as much contextual detail as possible.

Another common measure of episodic memory asks subjects to produce detailed and specific autobiographical recollections in response to single-word cues (e.g., holiday, bird, birthday). The modern version of the test was developed by Crovitz and Schiffman (1974; also Crovitz \& Quina-Holland, 1976) and was modeled after an experiment by Sir Francis Galton (1879). Although the task has gone by many different names, we will refer to it as the Galton-Crovitz test. For both tests, the veridicality of the recollections is typically checked against both the existing medical records and the memories of subjects' friends and family. Except for patients with syndromes of confabulation, it is generally found that individuals do not give inaccurate reports (Kopelman, Stanhope, \& Kingsley, 1999).

In other cases, researchers have assessed the episodic memory of patients via a structured interview that was constructed with knowledge about the specific details of that person's life history. By gathering relevant informa- 
tion from family members, it is possible to ask patients questions about episodes from their pasts (e.g., "Tell me about the time you climbed Mount Kilimanjaro"). The advantage of using these structured interviews is that it is relatively easy to assess the accuracy of the patients' answers. It is more difficult, however, to determine what impaired performance should look like, since there is no obvious control group available to take the same test. Still, some researchers have successfully used the structured interview to establish the temporal boundaries of FRA (Lucchelli et al., 1995; Yoneda et al., 1992).

There is a greater variety of tests available for the assessment of pretraumatic semantic memory. Some questions on the AMI (Kopelman et al., 1990) are classified as personal semantic; the questions probe different facts from varying time periods (e.g., "What was the name of your high school?" or "What was your wedding date?"). Such questions are thought to be part of a base of autobiographical, semantic knowledge, and episodic remembering is not typically necessary for successful performance. The authenticity of the responses can be checked in the same way as the episodic reports. Because the AMI is composed of both episodic and personal semantic components, it has the potential to find selective deficits in one or both aspects of autobiographical memory (see Calabrese et al., 1996, and Levine et al., 1998, for examples of dissociations between the two components).

It is also possible to tailor a structured interview to assess an individual's semantic memory. Patients are occasionally asked to recall facts that they had recently learned at work or school. For example, Yasuda et al. (1997) described a woman who, following surgical excision of a tumor, was unable to recall the banking terms that she had previously used as a part of her job (see also Grossi et al., 1988; Klein et al., 1996; Yoneda et al., 1992).

Most measures of semantic memory assess retention of facts that are not autobiographic and that have been acquired by large numbers of people. Some of the most common tests probe knowledge of things that were widely reported in the media. There are several versions of the Famous Events Test (Kroll, Markowitsch, Knight, \& von Cramon, 1997; Mattioli et al., 1996; Stuss \& Guzman, 1988), all of which assess the ability of subjects to report knowledge about events that got a great deal of media exposure for a limited period of time (e.g., eruption of Mount St. Helens). It is therefore possible to probe events that occurred in different decades to look at the time course of memory loss. Similarly, there are several varieties of the Famous Faces and Famous Names Tests, which measure the ability to identify and describe people who became well known during circumscribed periods of time (e.g., Lance Ito) on the basis of the person's face or name, respectively. Other researchers have used tests of semantic general knowledge (e.g., "What is the currency in France?" or "What is the child of a pig called?") to assess retention of facts about the world (De
Renzi et al., 1987; Markowitsch et al., 1993; Markowitsch et al., 1999).

\section{Results and Discussion}

The search revealed 35 cases of FRA. We first subdivided the patients on the basis of their retrograde memory abilities, according to their performance on the various episodic and semantic tests. In the next step, we considered each of the different classifications of FRA individually, with emphasis on lesion localization.

Initial classification. Only nine, or 26\%, of the patients exhibited deficits that could be classified as pure. There were five cases of purely episodic FRA, with no accompanying deficits on any of the semantic tasks. Another four cases exhibited the symptoms of pure semantic FRA, with fully intact episodic recollections for all life periods.

The majority of patients (26, or $74 \%$ ) experienced some combination of episodic and semantic deficits. It quickly became apparent that these cases could be further subdivided into three groups on the basis of the neuropsychological profiles of the patients. There were nine published case studies documenting a total loss of both episodic and semantic memory. In these instances, there was usually a temporal gradient, since the retrograde amnesia for both types of memory was confined to some circumscribed period of time directly preceding the trauma.

Another 16 patients had deficits in both episodic and semantic memory, yet the deficits were asymmetrical. All of the patients had a complete, or virtually complete, episodic FRA, since they were unable to clearly recollect even a single pretraumatic event. These symptoms were combined with a "patchy" semantic profile, since the patients were impaired in comparison with healthy control subjects on semantic tests. Still, they typically scored well above chance performance and clearly retained some knowledge about their own lives and also about events that were reported in the media.

Within this group, four patients displayed neuropsychological profiles that were different from the rest of the group and also similar to one another. In these cases, FRA was combined with a loss of visual imagery. It may be that the ability to form a visual image is necessary for normal episodic recollection and also for many instances of semantic retrieval. Below, we summarize each of the groups.

Episodic FRA > semantic FRA (no visual disturbances). The largest single group of patients were those with a complete loss of pretraumatic episodic recollections, combined with a reduced ability to semantically know about events from the pretraumatic past. These 12 cases are summarized in Table 1. The four patients with this profile who also had visual/imaginal disturbances are discussed in a separate section.

A recent case study provides a good example of the general syndrome (Tanaka, Miyazawa, Hashimoto, Nakano, \& Obayashi, 1999). A woman was hospitalized with severe seizures from a suspected case of herpes simplex encephalitis. After recovering from the seizures, the 
Table 1

Cases of Focal Retrograde Amnesia in Which Episodic Memory is Affected More Than Semantic Memory (No Visual Disturbances)

\begin{tabular}{|c|c|c|c|c|}
\hline First Author (year) & Etiology & $\begin{array}{l}\text { Imaging Source } \\
\text { and Lesion Site }\end{array}$ & Episodic Evidence & Semantic Evidence \\
\hline$\overline{\text { Calabrese (1996) }}$ & HSE & $\begin{array}{l}\text { MRI-R temporal pole, } \\
\mathrm{R} \text { inferior lateral prefrontal }\end{array}$ & AMI/E, G/C-very impaired & $\begin{array}{l}\text { AMI/PS, GKT, FF-mild } \\
\text { impairment }\end{array}$ \\
\hline De Renzi (1995) & $\mathrm{CHI}$ & CT, MRI, PET_normal & $\begin{array}{l}\text { SI-no recollections for } \\
\text { pretraumatic periods }\end{array}$ & $\begin{array}{l}\text { FE, FN-impaired at recall, } \\
\text { but recognition was normal; } \\
\text { GKT_-"gaps" in knowledge }\end{array}$ \\
\hline Kapur (1992) & $\mathrm{CHI}$ & $\begin{array}{l}\text { MRI_Bi temporal poles; } \\
\text { some bifrontal poles }\end{array}$ & $\begin{array}{l}\text { SI-no recollections for } \\
\text { pretraumatic periods }\end{array}$ & $\begin{array}{l}\text { SI-extremely impaired; } \\
\text { FF, FE, FN-impaired, but } \\
\text { better than chance performance }\end{array}$ \\
\hline Kapur (1994) & Radio-necrosis & $\begin{array}{l}\text { MRI-Bi inferior temporal } \\
\text { and temporal polar }\end{array}$ & $\begin{array}{l}\text { AMI/E, G/C_-"nonspecific" } \\
\text { memories for past episodes, } \\
\text { rather than detailed descriptions }\end{array}$ & $\begin{array}{l}\text { AMI/PS-perfect scores; } \\
\text { FF, FE-impaired }\end{array}$ \\
\hline \multicolumn{5}{|l|}{ Kapur (1996) } \\
\hline Patient 1 & $\mathrm{CHI}$ & $\begin{array}{l}\text { MRI, PET-extensive } \\
\text { L temporal; } \\
\text { R inferior temporal }\end{array}$ & $\mathrm{AMI} / \mathrm{E}$ —-very impaired & $\begin{array}{l}\text { AMI/PS_normal performance, } \\
\text { FN, GKT_impaired }\end{array}$ \\
\hline Patient 2 & $\mathrm{CHI}$ & $\begin{array}{l}\text { MRI-L temporal pole; } \\
\text { L anterior hippocampus }\end{array}$ & $\begin{array}{l}\mathrm{AMI} / \mathrm{E}, \mathrm{SI}-\text { no recollections } \\
\text { for pretraumatic periods }\end{array}$ & AMI/PS—mild impairment \\
\hline \multicolumn{5}{|l|}{ Kroll (1997) } \\
\hline Patient 1 & $\mathrm{CHI}$ & $\begin{array}{l}\text { MRI-Bi ventral frontal and } \\
\text { temporal polar; L temporal. }\end{array}$ & $\begin{array}{l}\mathrm{G} / \mathrm{C}, \mathrm{SI}, \mathrm{AMI} / \mathrm{E} \text {-very few } \\
\text { pretraumatic recollections }\end{array}$ & $\begin{array}{l}\text { AMI/PS, FE_-impaired; GKT- } \\
\text { normal; FF_-mild impairment }\end{array}$ \\
\hline Patient 2 & $\mathrm{CHI}$, meningitis & $\begin{array}{l}\text { MRI-L temporal pole } \\
\text { inferotemporal; and some } \\
\text { R temporal pole }\end{array}$ & $\begin{array}{l}\mathrm{G} / \mathrm{C}, \mathrm{SI}, \mathrm{AMI} / \mathrm{E} \text { - very few } \\
\text { pretraumatic recollections }\end{array}$ & $\begin{array}{l}\text { AMI/PS, GKT_normal; FE- } \\
\text { impaired; FF-mild impairment }\end{array}$ \\
\hline Levine (1998) & $\mathrm{CHI}$ & $\begin{array}{l}\text { MRI-R ventral frontal, } \\
\text { including uncinate fasciculus }\end{array}$ & $\begin{array}{l}\mathrm{AMI} / \mathrm{E}, \mathrm{G} / \mathrm{C}-\text {-no recollections } \\
\text { for pretraumatic periods }\end{array}$ & $\begin{array}{l}\text { AMI/PS—normal; SI- } \\
\text { some impairment }\end{array}$ \\
\hline Markowitsch (1993) & $\mathrm{CHI}$ & $\begin{array}{l}\text { MRI-Bi temporal poles and } \\
\text { inferior frontal; L temporo- } \\
\text { parietal }\end{array}$ & $\begin{array}{l}\mathrm{AMI} / \mathrm{E}, \mathrm{SI}-\mathrm{no} \text { recollections } \\
\text { for pretraumatic periods }\end{array}$ & $\begin{array}{l}\mathrm{AMI} / \mathrm{PS}, \mathrm{FF}, \mathrm{FN}, \mathrm{GKT}- \\
\text { impaired, but better than } \\
\text { chance performance }\end{array}$ \\
\hline Stuss (1988) & $\begin{array}{l}\text { seizures, possible } \\
\text { HSE }\end{array}$ & MRI, PET—L temporal pole & $\begin{array}{l}\text { SI-no recollections for } \\
\text { pretraumatic periods }\end{array}$ & $\begin{array}{l}\text { FE-very impaired at recall; } \\
\text { much better at recognition }\end{array}$ \\
\hline Tanaka (1999) & HSE & $\begin{array}{l}\text { MRI-Bi temporal pole; } \\
\text { R parahippocampal gyrus }\end{array}$ & $\begin{array}{l}\text { AMI/E_-virtually no } \\
\text { pretraumatic recall }\end{array}$ & $\begin{array}{l}\mathrm{AMI} / \mathrm{PS} \text {-impaired; FF, FE- } \\
\text { very impaired at recall; much } \\
\text { better at recognition }\end{array}$ \\
\hline
\end{tabular}

Note-HSE, herpes simplex encephalitis; CHI, closed-head injury; MRI, magnetic resonance imaging; CT, computed tomography; PET, positron emission tomography; AMI/E, Autobiographic Memory Interview/Episodic; G/C, Galton-Crovitz; SI, Structured Interview; AMI/PS, Autobiographic Memory Interview/Personal Semantic; FF, Famous Faces; FE, Famous Events; FN, Famous Names; GKT, General Knowledge Test; Bi, bilateral; L, left; R, right.

woman regained full orientation to time and place, and her behavior was socially appropriate. A few weeks after recovery, neuroimaging discovered pathology in the temporal poles bilaterally, as well as in the left insular cortex and its surrounding structures. Neuropsychological testing failed to reveal deficits in spontaneous speech, object naming, auditory comprehension, or general intelligence. Her anterograde memory may have been mildly impaired, but she was fully able to learn and retain new information.

These normal, or nearly normal, capacities could be contrasted with the patient's severe difficulty when attempting to remember information that had been well learned before the seizures. In a formal standardized questionnaire intended to assess different life periods, she was unable, for example, to recollect any events that she had experienced in either elementary or junior high school. Her episodic recollections of all pretraumatic periods was extremely weak, and although she could report about a few remote events, it is not clear whether these were valid cases of remote memories or whether she was simply reporting something that had been recently relearned. In contrast, performance on tests for semantic autobiographical knowledge was relatively spared, since she could report facts about her schooling and occupational history. On other semantic tests (Famous Faces, Famous Events), the patient showed a similar pattern; although performance was clearly disrupted in comparison with healthy control subjects, it was also evident that there was a substantial amount of preserved retrograde semantic information about both personal facts and famous events. It is this overall profile that represents all of the patients in this category.

Visual inspection of Table 1 reveals a number of similarities across the various cases. First, there was no evidence of a temporal gradient to the retrograde amnesia. This fact helps to distinguish these patients from several other FRA cases (Fujii et al., 1999; Hokkanen, Launes, Vataja, Valanne, \& Iivanainen, 1995; Klein et al., 1996; Stracciari et al., 1994; Yoneda et al., 1992) and also reinforces the point that the syndrome of FRA is functionally different than the retrograde amnesia that occurs in 
conjunction with anterograde amnesia following medial temporal damage. In these latter cases, which comprise the majority of patients with retrograde deficits, the retrograde amnesia is nearly always confined to some limited period of time directly preceding the traumatic event (although there are some exceptions; see Nadel \& Moscovitch, 1997).

Perhaps most important, the temporal polar cortex is consistently implicated. Across the 12 patients, 10 had a lesion encroaching upon either one or both of the temporal poles; there were five cases of documented bilateral pathology, and one case of unilateral right and four of unilateral left temporal polar damage. In another patient (Levine et al., 1998), the primary lesion was in the right uncinate fasciculus, a fiber tract interconnecting the ventral frontal region with the temporal poles (Pandya \& Barnes, 1987). Operations of this fiber tract were similarly disrupted in at least one of the other patients (Markowitsch et al., 1993).

The prevalence of temporal polar injuries in cases of FRA has been noted by other researchers (De Renzi et al., 1997; Fujii et al., 1999; Kapur, 1999; Kapur et al., 1992; Markowitsch et al., 1993), although this area is not found consistently in FRA. This analysis has revealed a likely reason for the inconsistent findings: Injuries to the temporal poles are associated with one category of FRA, but not with other categories. Support for this assertion comes from a comparison with other classes of FRA patients. Of the 23 patients in the other four categories, only 3 had damage encroaching upon or affecting this region (Maravita et al., 1995, Markowitsch et al., 1999; O'Connor et al., 1992), as compared with 11 out of 12 in this category. We conducted a chi-square test to formalize the question of whether this distribution of lesion localization could be expected by random, or chance, factors. The analysis was significant $\left[\chi^{2}(3)=20.31, p<.001\right]$, implying the presence of a distinct syndrome of FRA implicating episodic memory more than semantic memory and not accompanied by visual disturbances.

Findings do not support previous ideas about hemispheric specificity with respect to episodic and semantic memory. Inspired by the consistent findings of positron emission tomography (PET) experiments using healthy adult subjects (Tulving, Kapur, Craik, Moscovitch, \& Houle, 1994), some researchers have suggested that right-hemisphere lesions, especially those affecting the frontal and temporal poles, specifically disrupt remote episodic memory, whereas similar left-hemisphere damage has a primary effect on remote semantic retrieval (Levine et al., 1998; Markowitsch et al., 1999). Summarizing across cases (see Table 1), the majority of patients had bilateral pathology, and for the remainder, there was no consistent relation between type of memory and affected hemisphere. Also, given that the majority of patients had suffered a closed-head injury, there may have been some microscopic, undetected lesions of the contralateral hemisphere in the patients who were classified as unilateral. This is an especially reasonable possibility given that these patients (Calabrese et al., 1996; Kapur et al., 1996; Levine et al., 1998; Stuss \& Guzman, 1988) all had etiologies (closed-head injury or encephalitis) that often affect multiple, distributed areas of the neocortex. It may be the case that bilateral alterations are necessary before an individual will show a complete, or nearly complete, loss of retrograde episodic recollections combined with impaired retrograde semantic knowledge. Given the current limitations of structural and functional neuroimaging, this possibility can be neither strongly supported nor refuted.

One of the case studies in this category does not resemble the others (De Renzi, Lucchelli, Muggia, \& Spinnler, 1995). This case involved a young man who was struck by a car while riding his bicycle. Unlike the other patients described in this category, it is not certain that he ever lost consciousness after the accident, and there was no evidence of injury to his face or head. The patient was unable to recollect even a single event that he had experienced prior to his accident and was initially unable to report his name, address, or any information about his family, although he relearned these facts very quickly. Neuropsychological testing confirmed his complete loss of retrograde episodic memory and demonstrated a "patchy" and moderately impaired profile on tests of retrograde semantic memory, combined with excellent anterograde memory skills. Repeated attempts at structural and functional neuroimaging (CT, MRI, PET) consistently failed to discover any abnormality. The authors considered, then rejected, the possibility that the patient's FRA could be accurately classified as psychogenic. Largely because there was no history of psychiatric or emotional disturbances and there was no evidence, or motivation, for malingering, De Renzi et al. (1995) suggest the term functional retrograde amnesia as an appropriate descriptor. The term implies that the memory disturbance exists in the absence of any documented cerebral injury and does not preclude the possibility that microscopic changes may be causing the amnesia. Despite the similarity in terms of episodic and semantic symptoms (episodic impaired more than semantic), it seems unlikely that this patient truly bears a strong resemblance to the other patients subsumed under this category.

Episodic FRA > semantic FRA (visual disturbances). There were four patients who demonstrated a retrograde amnesia that was, in many ways, similar to that described in the previous section: a profound loss of pretraumatic episodic recollection, combined with a lesser impairment on tests of retrograde semantic knowledge. Also, there was no temporal gradient present in any of the patients. These cases are summarized in Table 2 .

The best-known example of an FRA patient with visual deficits was reported by O'Connor et al. (1992). After hospitalization for a severe episode of encephalitis, a young woman suffered from profound visuoperceptual deficits, especially when she attempted to generate detailed visual information from memory. The patient was unable to recollect any personal episodes that occurred 
Table 2

Cases of Focal Retrograde Amnesia in Which Episodic Memory is Affected More Than Semantic Memory (Visual Disturbances)

\begin{tabular}{|c|c|c|c|c|}
\hline First Author (year) & Etiology & $\begin{array}{l}\text { Imaging Source } \\
\text { and Lesion Site }\end{array}$ & Episodic Evidence & Semantic Evidence \\
\hline Brown (1995) & $\mathrm{CHI}$ & MRI-L occipital; R frontal & $\begin{array}{l}\text { SI-no recollections for } \\
\text { pretraumatic periods }\end{array}$ & $\begin{array}{l}\text { SI-impaired, but better than } \\
\text { chance performance }\end{array}$ \\
\hline Hunkin (1995) & $\mathrm{CHI}$ & $\begin{array}{l}\text { MRI-R parieto-occiptal; } \\
\text { L inferior occipital; Bi medial } \\
\text { occipital }\end{array}$ & $\begin{array}{l}\mathrm{AMI} / \mathrm{E}, \mathrm{G} / \mathrm{C}-\text { no recollections } \\
\text { for pretraumatic periods }\end{array}$ & $\begin{array}{l}\text { AMI/PS-normal; FF, FE- } \\
\text { impaired, but better than } \\
\text { chance performance }\end{array}$ \\
\hline O’Connor (1992) & HSE & $\begin{array}{l}\text { CT, MRI-extensive R temporal; } \\
\text { R occipital and parietal }\end{array}$ & $\begin{array}{l}\text { SI-no recollections for } \\
\text { pretraumatic periods }\end{array}$ & $\begin{array}{l}\text { SI, FE-impaired, but better } \\
\text { than chance performance }\end{array}$ \\
\hline Ogden (1993) & $\mathrm{CHI}$ & $\begin{array}{l}\text { MRI-Bi medial occipital, in- } \\
\text { cluding underlying white matter }\end{array}$ & $\begin{array}{l}\text { AMI/E } \\
\text { extremely impaired }\end{array}$ & AMI/PS—some impairment \\
\hline
\end{tabular}

Note-CHI, closed-head injury; HSE, herpes simplex encephalitis; MRI, magnetic resonance imaging; CT, computed tomography; AMI/E, Autobiographic Memory Interview/Episodic; G/C, Galton-Crovitz; SI, Structured Interview; AMI/PS, Autobiographic Memory Interview/Personal Semantic; FF, Famous Faces; FE, Famous Events; Bi, bilateral; L, left; R, right.

before the onset of her illness, despite the ability to retrieve some of the semantic aspects of autobiographical events. The authors suggested that the patient's FRA may have been partly or wholly a result of her lack of visual imagery.

The other cases presented similar memory syndromes, also combined with visual/perceptual deficits. A patient described by Ogden (1993) suffered from even more severe perceptual disturbances, including visual object agnosia, prosopagnosia, and achromatopsia, or loss of color memory. The visual problems of the other patient (described by Hunkin et al., 1995) were more subtle, but included marked impairments on visual, but not verbal, anterograde recall and recognition tests.

Patients in this group present a lesion profile that is distinct from other FRA patients. Consistent with the disruption of visual/imaginal functioning, pathology was typically confined to the posterior neocortex, especially the parietal, occipital, and temporal regions comprising the striate and extrastriate cortices. In one of the cases (O'Connor et al., 1992), there was also extensive righttemporal-lobe damage that included the temporal pole, implying that this patient might also belong to the previous category of FRA.
Although only four cases proved suitable for inclusion, there is strong evidence from other sources that extensive retrograde amnesia can result from posterior cortical damage, including lesions that spare both the medial temporal areas and the temporal poles. In a recent review, Rubin and Greenberg (1998) identified several patients with both amnesia (retrograde or anterograde) and deficits in visual imagery. They named the general syndrome visual memory-deficit amnesia and argued that, in each case, the memory disorder was secondary to damage to areas of the visual system that operate on visual information. Many of these cases could not be classified as FRA because the extent of the anterograde amnesia was too severe or because there had been insufficient testing to accurately determine the extent of the retrograde loss. Still, a number of the patients did meet the criteria for inclusion at FRA patients, suggesting that there is some important relation between the visual system and retrograde memory.

Semantic FRA. Four patients demonstrated FRA that was confined to semantic memory. These cases are summarized in Table 3. In each instance, affected patients had no difficulty recollecting pretraumatic personal experiences. The patient described earlier (from Grossi

Table 3

Cases of Focal Retrograde Amnesia With a Selective Loss of Semantic Memory

\begin{tabular}{lllll}
\hline First Author (year) & Etiology & \multicolumn{1}{c}{$\begin{array}{c}\text { Imaging Source } \\
\text { and Lesion Site }\end{array}$} & \multicolumn{1}{c}{ Episodic Evidence } & Semantic Evidence \\
\hline De Renzi (1987) & possible virus & $\begin{array}{l}\text { CT, MRI-L posterior and for } \\
\text { all inferior temporal; some } \\
\text { amygdala and hippocampus } \\
\text { CT-L parietal }\end{array}$ & $\begin{array}{l}\text { SI - detailed and accurate } \\
\text { for all life periods }\end{array}$ & FF, FN, GKT-extremely poor \\
Grossi (1988) & CHI & SI-no impairments & $\begin{array}{l}\text { FF - impaired; SI - could not } \\
\text { report things she had learned } \\
\text { in school } \\
\text { AMI/PS - normal; FF, FE, } \\
\text { Markowitsch (1999) }\end{array}$ \\
CHI & surgical excision & $\begin{array}{l}\text { CT-L ventral frontal, } \\
\text { temporal polar } \\
\text { MRI-Bimpaired } \\
\text { R basal frontal }\end{array}$ & AMI/E, G/C-normal & SI, FF, FN, FE-impaired \\
\hline
\end{tabular}

Note-CHI, closed-head injury; CT, computed tomography; MRI, magnetic resonance imaging; AMI/E, Autobiographic Memory Interview/ Episodic; G/C, Galton-Crovitz; SI, Structured Interview; AMI/PS, Autobiographic Memory Interview/Personal Semantic; FF, Famous Faces; FE, Famous Events; FN, Famous Names; GKT, General Knowledge Test; Bi, bilateral; L, left; R, right. 
et al., 1988) fits into this category, since she could neither retrieve most of the information she had recently learned about in school nor recognize famous people and events that had been widely reported in the media prior to her head injury. Still, she could remember such seemingly trivial incidents as the act of sitting in her classroom and talking to her teacher.

All the patients had documented neuropathology in the left hemisphere (either temporal or parietal), which is compatible with the idea that this hemisphere is particularly important for language-based "semantic" processing. But there was no other striking consistency with respect to lesion localization. In other patients with diagnoses of semantic dementia (Snowden, Neary, \& Mann, 1996) or associative agnosia (Warrington \& Shallice, 1984), there is often a disruption of left-temporal functioning, as well as a semantic retrograde amnesia that is usually part of a more general semantic memory disorder (Kapur, 1999). So, although there appears to be a general trend pointing to the importance of the left temporal cortex, more patients will have to be identified and studied before any firm conclusions can be drawn.

The existence of semantic FRA is compatible with more recent formulations about the relations between the two memory systems. It has recently been argued that retrieval from the episodic and the semantic memory occurs independently (Tulving \& Markowitsch, 1998), and the discovery that retrograde amnesia can disrupt semantic, but not episodic, retrieval is a counterintuitive finding that lends some support to the proposal.

Episodic FRA. There are five published cases describing patients with an FRA that is confined to episodic memory. In each instance, there is a complete lack of pretraumatic recollections covering some period of time, yet it is also clear that the patient is able to know about things that happened during the amnesic period. These cases are summarized in Table 4.

Perhaps the most dramatic example of episodic FRA involves a woman who became amnesic following an at- tack of cerebral vasculitis (Evans, Breen, Antoun, \& Hodges, 1996). Across a number of different neuropsychological tests, she was unable to recollect any pretraumatic experiences, except for some vague memories from early childhood. Yet she was able to report much of her autobiography. For example, the patient knew that she had been on many vacations and described Venice as her favorite city, despite the lack of even a single episodic memory of being on a vacation.

In other cases of episodic FRA, there is a temporal gradient, and the amnesia has resolved after several months. For example, a first-year college student became amnesic following a closed-head injury and was unable to recollect anything from the previous 6 months, rendering her amnesic for her college, but not her precollege, life (Klein et al., 1996). Yet the woman knew the names of courses she had taken and the names of friends and teachers that she had met during this time. A few months after the onset of amnesia, she suddenly recovered her recollections from the amnesic period. This was not simply a case of relearning about past experiences, since the young woman was able to describe pretraumatic collegiate experiences that had not been described to her since the accident. Two similar cases were reported by Stracciari et al. (1994), also following minor head injuries. Because these three patients presented such similar symptoms, it seems reasonable to regard this temporally graded, transient episodic FRA as a distinct subset of all FRA cases.

From visual inspection of Table 4, an interesting pattern emerges with respect to lesion localization. In four of the five cases, structural neuroimaging failed to discover any organic brain injury, although two of these patients (Maravita et al., 1995; Stracciari et al., 1994, Patient 1 ) did have some mild reductions in cortical activity discovered by PET. The remaining patient (Evans et al., 1996) had injuries to the frontal lobes bilaterally, as well as the left temporal pole, although this patient did not present with the same amnesic profile as most FRA patients with temporal polar lesions.

Table 4

Cases of Focal Retrograde Amnesia (FRA) With a Selective Loss of Episodic Memory

\begin{tabular}{|c|c|c|c|c|}
\hline First Author (year) & Etiology & $\begin{array}{l}\text { Imaging Source } \\
\text { and Lesion Site }\end{array}$ & Episodic Evidence & Semantic Evidence \\
\hline Evans (1996) & cerebral vasculitis & $\begin{array}{l}\text { MRI-Bi frontal; L parietal; } \\
\text { L temporal pole }\end{array}$ & $\begin{array}{l}\mathrm{AMI} / \mathrm{E}, \mathrm{G} / \mathrm{C}, \mathrm{SI}-\text { very few } \\
\text { recollections from pretraumatic } \\
\text { periods }\end{array}$ & AMI/PS, FF, FE - normal; \\
\hline Klein (1996)* & $\mathrm{CHI}$ & $\mathrm{CT}$-normal & $\begin{array}{l}\mathrm{G} / \mathrm{C}-\text { no recollections from } \\
\text { several months prior to } \mathrm{CHI}\end{array}$ & SI-no impairment \\
\hline Maravita (1995) & $\mathrm{CHI}$ & $\begin{array}{l}\text { MRI, EEG-normal; PET- } \\
\text { slight L temporal hypoperfusion }\end{array}$ & $\mathrm{SI}, \mathrm{G} / \mathrm{C}-$ no recollections & GKT_no impairment $\dagger$ \\
\hline $\begin{array}{l}\text { Stracciari }(1994)^{*} \\
\text { Case } 1\end{array}$ & $\mathrm{CHI}$ & $\begin{array}{l}\text { MRI, EEG-normal; SPECT- } \\
\text { L frontal hypoperfusion }\end{array}$ & $\begin{array}{l}\mathrm{G} / \mathrm{C}-\text { no recollections from } \\
\text { year prior to } \mathrm{CHI}\end{array}$ & $\begin{array}{l}\mathrm{FE}, \mathrm{FF} \text {-normal for all } \\
\text { life periods }\end{array}$ \\
\hline $\begin{array}{l}\text { Stracciari }(1994)^{*} \\
\text { Case } 2\end{array}$ & $\mathrm{CHI}$ & CT, EEG, PET-normal & $\begin{array}{l}\mathrm{G} / \mathrm{C} \text { - no recollections from } \\
\text { year prior to } \mathrm{CHI}\end{array}$ & $\begin{array}{l}\text { FE, FF-normal for all } \\
\text { life periods }\end{array}$ \\
\hline
\end{tabular}

Note-CHI, closed-head injury; MRI, magnetic resonance imaging; CT, computed tomography; PET, positron emission tomography; EEG, electroencephalogram; SPECT, single proton emission computed tomography; AMI/E, Autobiographic Memory Interview/Episodic; G/C, GaltonCrovitz; SI, Structured Interview; AMI/PS, Autobiographic Memory Interview/Personal Semantic; FF, Famous Faces; FE, Famous Events; GKT, General Knowledge Test; Bi, bilateral; L, left. *The FRA resolved within a year following the accident. †Immediately following the injury, amnesia encompassed both semantic and episodic memory, and semantic RA had resolved. 
Table 5

Cases of Focal Retrograde Amnesia (FRA) in Which There are Equivalent Losses of Episodic and Semantic Memory

\begin{tabular}{|c|c|c|c|c|}
\hline First Author (year) & Etiology & $\begin{array}{l}\text { Imaging Source } \\
\text { and Lesion Site }\end{array}$ & Episodic Evidence & Semantic Evidence \\
\hline Carlesimo (1998) & HSE & $\begin{array}{l}\text { MRI-Bi }(\mathrm{L}>\mathrm{R}) \text { temporal } \\
\text { (poles and hippocampi spared), } \\
\text { parietal, occipital }\end{array}$ & $\begin{array}{l}\text { SI-very impaired, especially } \\
\text { for most recent } 15 \text { years }\end{array}$ & $\begin{array}{l}\text { FF, FN-impaired; FE- } \\
\text { impaired, especially for most } \\
\text { recent } 15 \text { years }\end{array}$ \\
\hline De Renzi (1993) & hypoxia & $\begin{array}{l}\text { MRI-normal; PET- } \\
\text { Bi posterior-temporal } \\
\text { hypometabolism }\end{array}$ & $\begin{array}{l}\mathrm{AMI} / \mathrm{E} \text {-no recollections } \\
\text { for any life period }\end{array}$ & $\begin{array}{l}\text { AMI/PS, FN, FF, FE-massively } \\
\text { impaired }\end{array}$ \\
\hline De Renzi (1997) & $\mathrm{CHI}$ & $\begin{array}{l}\text { CT, MRI, SPECT, EEG- } \\
\text { normal }\end{array}$ & $\begin{array}{l}\text { AMI/E_no recollections for } \\
\text { any life period }\end{array}$ & $\begin{array}{l}\mathrm{FF}, \mathrm{FE}, \mathrm{FN}, \mathrm{GKT} \text { - at chance } \\
\text { levels }\end{array}$ \\
\hline Fujii (1999) & HSE & $\begin{array}{l}\text { MRI, SPECT-Bi medial } \\
\text { temporal, including anterior } \\
\text { hippocampus }\end{array}$ & $\begin{array}{l}\mathrm{AMI} / \mathrm{E}-\text { sketchy recollections, } \\
\text { especially for several recent } \\
\text { years }\end{array}$ & $\begin{array}{l}\mathrm{AMI} / \mathrm{PS}, \mathrm{FE}-\text { amnesia limited to } \\
\text { the preceding } 10 \text { years }\end{array}$ \\
\hline Hokkanen (1995) & HSE & $\begin{array}{l}\text { CT, MRI—normal; EEG- } \\
\text { L temporal slowing }\end{array}$ & $\begin{array}{l}\text { AMI/E_impaired for several } \\
\text { years prior to trauma; } \\
\text { childhood normal }\end{array}$ & $\begin{array}{l}\text { AMI/PS-impaired for several } \\
\text { years prior to trauma; childhood } \\
\text { normal }\end{array}$ \\
\hline Kapur (1989) & $\begin{array}{l}\text { temporal lobe } \\
\text { epilepsy }\end{array}$ & $\begin{array}{l}\text { MRI-no structural lesion; } \\
\text { EEG_L temporal }\end{array}$ & $\begin{array}{l}\text { AMI/E_normal score, but } \\
\text { no recollection of some } \\
\text { specific past events }\end{array}$ & $\begin{array}{l}\text { AMI/PS-unimpaired; FF, FE- } \\
\text { impaired; normal performance } \\
\text { on test of famous cars }\end{array}$ \\
\hline Lucchelli (1995)* & $\mathrm{CHI}$ & $\begin{array}{l}\mathrm{CT}, \mathrm{MRI}-\text { normal; PET- } \\
\text { reduced activity in posterior } \\
\text { cingulate cortex }\end{array}$ & $\begin{array}{l}\text { SI-amnesic for all years } \\
\text { except for a few "patchy" } \\
\text { episodes }\end{array}$ & $\begin{array}{l}\text { SI, FE-amnesic for all events; } \\
\text { no temporal gradient }\end{array}$ \\
\hline Mattioli (1996) & $\mathrm{CHI}$ & $\begin{array}{l}\mathrm{CT}, \mathrm{MRI}-\text { normal; } \mathrm{PET}- \\
\text { reduced activity in } \mathrm{Bi} \\
\text { hippocampus, anterior } \\
\text { cigulate cortex }\end{array}$ & $\begin{array}{l}\text { SI-no recollections for the } \\
\text { preceding } 30 \text { years, but normal } \\
\text { memory for childhood }\end{array}$ & $\begin{array}{l}\text { FE_-scored at chance levels; } \\
\text { GKT_knew only about her } \\
\text { childhood }\end{array}$ \\
\hline Reinvang (1998) & headaches & $\begin{array}{l}\text { CT, MRI, SPECT, PET- } \\
\text { normal; EEG-L fronto- } \\
\text { temporal abnormality }\end{array}$ & $\begin{array}{l}\mathrm{AMI} / \mathrm{E}, \mathrm{G} / \mathrm{C}-\text {-no recollections } \\
\text { for preceding } 15-20 \text { years }\end{array}$ & $\begin{array}{l}\text { FE, FN-amnesia limited to the } \\
\text { preceding } 15-20 \text { years }\end{array}$ \\
\hline Yoneda (1992) & HSE & $\begin{array}{l}\text { CT, MRI—normal; SPECT- } \\
\text { L temporal abnormality }\end{array}$ & $\begin{array}{l}\text { SI-amnesic for year prior } \\
\text { to illness }\end{array}$ & $\begin{array}{l}\text { SI-not extensively tested, but } \\
\text { did not know about major news } \\
\text { events from the preceding year }\end{array}$ \\
\hline
\end{tabular}

Note-HSE, herpes simplex encephalitis; CHI, closed-head injury; MRI, magnetic resonance imaging; CT, computed tomography; PET, positron emission tomography; EEG, electroencephalogram; SPECT, single proton emission computed tomography; AMI/E, Autobiographic Memory Interview/Episodic; G/C, Galton-Crovitz; SI, Structured Interview; AMI/PS, Autobiographic Memory Interview/Personal Semantic; FF, Famous Faces; FE, Famous Events; FN, Famous Names; GKT, General Knowledge Test; Bi, bilateral; L, left; R, right. *FRA resolved after several weeks.

Failure to discover organic brain injuries in the majority of cases of episodic FRA is intriguing, especially because the patients do not fit the typical profile of psychogenic amnesia. In each instance, there was a lack of previous psychiatric disease or personality disorders, and there was never a loss of personal identity. Furthermore, the onset of amnesia followed a closed-head injury, and none of the patients sought or received any financial benefits from their conditions. All the cases in this group arguably represent valid examples of organic FRA, despite the failure to discover major neocortical or subcortical lesions.

Episodic and semantic (equivalent losses). There were 10 examples of FRA that encompassed both episodic and semantic memory equally, or at least roughly equally. The cases are summarized in Table 5. Visual inspection of the table reveals that there are not many commonalities across all of the cases. Perhaps the most striking finding is that, once again, for the majority of patients (8 out of 10), structural imaging did not demonstrate evidence of any physical brain injury, although functional imaging (SPECT, PET, or EEG) identified reduced activity in 7 of these 8 cases. The instances may be best classified as functional retrograde amnesias. We are in agreement with De Renzi et al. (1997) that it is not desirable to diagnose such patients with psychogenic amnesia. Especially in the absence of any psychiatric history, the term functional implies that any brain injuries or changes that have occurred have effects on neurophysiology, but not necessarily on neuroanatomy.

There was a lack of consistency with respect to the presence or absence of temporal gradients and, when present, the extent of the gradient. In four cases, the FRA extended throughout all life periods, while the remainder were amnesic for some circumscribed period of time immediately prior to their injury. The extent of these amnesic periods ranged from approximately 1 year (Yoneda et al., 1992) to approximately 30 years (Mattioli et al., 1996). Notable, however, was the fact that the episodic and the semantic evidence followed the same time course for each patient. In the case described by Reinvang and Gjerstad (1998), for example, a man became densely amnesic for a 15-20 year period, with the retrograde amnesia covering all episodic recollections and knowledge about public events during that time period, while completely sparing retrograde memories from all other periods of time. The evidence implies that episodic and semantic memories are unlikely to be stored completely independently or 
that they at least share some common retrieval component. Results also strongly imply that each memory trace must somehow include information about the time of encoding. In several cases, the factor that determined whether or not a pretraumatic memory could be retrieved was the age of the memory, and not any of the other factors that are known to affect encoding, storage, and retrieval (e.g., personal saliency, level of processing, modality).

At least four of the patients in this category exhibited a symptom that is highly unusual. In addition to episodic and semantic deficits, they were also unable to show various kinds of procedural learning that they had acquired during the period for which they were amnesic (De Renzi et al., 1997; Lucchelli et al., 1995; Mattioli et al., 1996; Reinvang \& Gjerstad, 1998). For example, the woman described by Mattioli and colleagues suffered a severe loss of skills, such as driving, knitting, cooking, and singing, and these were all activities at which she had been very proficient before her trauma. She was able to relearn these skills at a seemingly normal rate, yet it is not clear that that was even any evidence of savings from her pretraumatic activities. Skill learning is generally classified as nondeclarative memory and is readily dissociable from episodic and semantic memory. Therefore, these cases represent a challenge to researchers studying the neuroscience of memory. They suggest that a wide range of procedural and declarative varieties of memory can be profoundly and equally disrupted, even when the neural substrates that support the encoding of these kinds of memory are apparently unharmed.

\section{GENERAL DISCUSSION}

Historically, the neural structures most closely associated with amnesia have been those in the medial temporal cortices. It is well established that damage to the hippocampal system will result in a loss of the ability to establish new episodic and semantic memories. Yet the syndrome of anterograde amnesia that typically follows medial temporal injuries should be considered as only one kind of amnesia. Patients with FRA only rarely have injuries implicating this brain area.

Our review demonstrated a number of points about FRA. First, the majority of FRA cases appear to differentially impact episodic and semantic memory. Across the 35 instances, there were only 10 cases in which episodic and semantic retrieval were disrupted to a similar extent; in these cases, both the severity and the time course of the amnesia were identical for the two forms of memory. Yet in another 9 patients, the FRA was confined entirely to either episodic memory (5 cases) or semantic memory (4 cases). Another 16 patients exhibited asymmetrical deficits: pretraumatic episodic recollections that were massively impaired, combined with smaller deficits for pretraumatic semantic knowledge.

These findings give support to the proposed distinction between the two forms of memory, although they also imply that there are both similarities and differences in the retrieval mechanisms for episodic and semantic memory and that it may not be appropriate to characterize retrieval from the two systems as truly independent. It is more reasonable to believe that the retrieval of remote memories from each system involves many complex neurocognitive processes, as well as a number of distributed cortical and subcortical areas. Although some, or even many, components of the retrieval networks may be devoted solely to one memory system or the other (leading to the finding of a retrograde amnesia that spares one form of memory, while disrupting the other), there are probably also overlapping components.

It is interesting that in a large majority of FRA cases demonstrating asymmetry (21 out of 25 ), episodic memory was more impaired than semantic memory. Although there are relatively few cases, the asymmetry is highly significant by a sign test. One likely explanation is that episodic memory traces are more vulnerable to disruption, perhaps because successful episodic retrieval requires the reactivation of a number of diverse, distributed components, more than would be required for an act of semantic knowing. Another possibility is that many additional cases of purely semantic FRA exist but have not been adequately identified or described. A selective disruption in knowing about the past might not be recognized as a memory disorder; it might, instead, be interpreted as a case of agnosia or aphasia and be handled differently by a clinician or experimenter.

A number of cases also reinforce the distinction between episodic and autobiographical memory. Although these two terms are often used interchangeably, a number of patients presented symptoms of FRA that devastated the recollection of pretraumatic episodes yet left nonepisodic autobiographical knowledge virtually intact (Calabrese et al., 1996; Evans et al., 1996; Hunkin et al., 1995; Kapur et al., 1994; Kapur et al., 1996; Klein et al., 1996; Kroll et al., 1997; Levine et al., 1998; Ogden, 1993). In each case, the patients were able to know many facts about their pretraumatic lives; for example, a woman knew that her house had been burgled twice, yet she could not recollect any details about the incidents (Evans et al., 1996). So, although recollecting the events of one's life can be considered to be both episodic and autobiographical, much of one's life story is represented in neurocognitive systems other than the episodic. Therefore, we prefer to consider the term autobiographical memory as a purely psychological construct, referring to the memory for, and knowledge about, oneself, without reference to neural substrates.

Perhaps the most important result of our analysis was the revelation that several cases appear to cluster together to form coherent categories of the overall syndrome. The presence of the clusters is critical; their existence allows for further discovery of the relations between neuroanatomy and cognitive abilities. It is also important to point out that the clusters were discovered through the use of the episodic-semantic distinction as an organizing tool. In a recent summary of a number of cases of FRA 
(Kapur, 1999), it was acknowledged that many, but not all, of the relevant cases showed dissociations between episodic and semantic memory, but little else could be concluded about the neural correlates of the syndrome. Across the various cases, there was a lot of variability with respect to specific symptoms and also with respect to lesion location. When we organized the case studies according to the specific episodic and semantic retrograde profiles of the patients, some semblance of order emerged, although the order was far from complete.

The most common cluster consisted of patients with a severe, often complete, inability to recollect any pretraumatic events, combined with a performance on semantic tests that was clearly impaired, yet also well above chance levels. In the majority of cases, these asymmetrical deficits were associated with pathology in the anterior temporal lobes or a disruption in the pathways leading to this area.

It is interesting that injuries to the temporal poles do not always result in a profound amnesia, although the injuries have been found to disrupt retrograde episodic memory. In their study with patients with unilateral temporal lobe epilepsy, Viskontas, McAndrews, and Moscovitch (2000) found deficits in the episodic component of the AMI, combined with normal levels of performance on the personal semantic component of this test. But the episodic impairment was not complete, since patients were still capable of recollecting some pretraumatic experiences. Also, the deficit was equivalent for postoperative patients, all of whom had a temporal pole resected, and those patients who were still awaiting surgery, whose temporal poles were presumably intact. The authors discussed the possibility that seizure activity may have disrupted temporal polar activity in all of the patients but were unable to localize the selective episodic deficit to any specific area within the temporal lobe. Further evidence will be necessary to determine the types of injuries that produce FRA. Although the syndrome can occur in conjunction with temporal polar lesions, it appears that such an injury is not always sufficient to produce FRA.

The temporal poles have been characterized as the integration cortex, because they are reciprocally connected to every sensory association area, as well as to multiple limbic and thalamic nuclei (Damasio, Eslinger, Damasio, Hoesen, \& Cornell, 1985; Markowitsch, Emmans, Irle, Streicher, \& Preilowski, 1985). This area is well situated to provide a link to the multimodal traces that are required for the complex retrieval of remote memories. Some researchers have explicitly theorized that FRA occurs when there is a disruption of the pathways interconnecting the temporal poles with the rest of the association cortex and limbic structures (Markowitsch et al., 1993). In at least one published case (Levine et al., 1998), pathology was not located in the anterior temporal cortex per se but, rather, in the uncinate fasciclus, a white matter tract connecting the temporal poles to the ventral frontal cortex.

One of the first explicit models of anterior temporal functioning in episodic memory (Damasio, 1989) de- scribed this brain area as one of the convergence zones responsible for the integration of multiple fragments of an experience. The components of each memory trace are distributed throughout many regions of single-modality cortices. Via reciprocal connections, each convergence zone serves to direct the synchronized firing of the widespread fragment records at retrieval, leading to a single unified recollection. By this view, the temporal poles are not storage sites but, rather, play a more supervisory role in directing and guiding time-locked ensemble firing patterns in distributed areas in the posterior cortices. Although Damasio argued that there were probably multiple convergence zones, his framework is compatible with the finding of massive retrograde amnesia following anterior temporal injuries. Recent researchers have accepted and extended parts of these ideas (De Renzi et al., 1997; Kroll et al., 1997) and have also noted the asymmetrical deficits, with pretraumatic episodic recollections being generally more affected than semantic memory.

Another set of patients may belong in this same cluster. Some patients with FRA present a similar memory profile with respect to episodic and semantic memory, combined with impaired performance on a number of visual/perceptual tests. This pattern of deficits, termed visual memory-deficit amnesia (Rubin \& Greenberg, 1998), typically accompanies posterior cortical damage, especially in the occipital lobes. Although the presence of visual imagery disturbances serves to distinguish this memory disorder from that accompanying temporal polar injuries, the strong similarities in episodic and semantic performance suggest that there may be a common retrieval mechanism that is impaired in the two groups. Indeed, Rubin and Greenberg argue that the inability to maintain a pattern of activation in visual areas may be disrupting the operations in areas of the nonvisual cortex to which it is normally projected, leading to a global impairment in episodic memory that extends beyond a simple loss of visual memory.

Converging evidence from functional neuroimaging is consistent with the roles of both anterior temporal and occipital cortices in the episodic retrieval. Two independent experiments with PET have compared the episodic recollection of autobiographical events to similar, nonepisodic conditions that required both complex retrieval and mental imagery. In the first study, episodic retrieval preferentially activated the right prefrontal and temporal cortex, including the temporal poles, as well as the hippocampal system, as compared with a nonepisodic condition that involved both mental imagery and the complex retrieval of biographical information about another person (Fink et al., 1996). More recently, Maguire and Mummery (1999) have contrasted the neural signatures of episodic recollection of autobiographical events (e.g., "You were Mike's best man at his wedding") with semantic retrieval of autobiographical facts (e.g., "Ray is the youngest of your brothers"). The episodic retrieval showed additional activity in the medial frontal cortex, the hippocampi, and the temporal poles. 
In a similar study, subjects retrieved autobiographical, episodic memories to cue words as cortical activity was mapped via electroencephalogram (Conway \& PleydellPearce, 2000). During the earliest stages of retrieval, the anterior temporal and frontal regions became active bilaterally. Very quickly, however, the activity shifted to bilateral occipital and posterior temporal areas, especially during the recollection of distinctive or vivid events. The authors concluded that a stable pattern of activation was formed in the posterior/sensory cortices and linked to an anteriorly generated retrieval model, resulting in a successful episodic recollection.

Evidence from neuroimaging, combined with an analysis of FRA patients, suggests the possible existence of a distinct memory disorder, one that is related, but not identical, to other varieties of amnesia that have been previously documented. The disruption of a neural network that encompasses regions of both the anterior temporal cortices and more posterior visual cortices results in a memory disorder that devastates retrograde episodic memory, while having a noticeable, yet smaller, impact on retrograde semantic memory. Previous researchers (Damasio, 1989; Rubin \& Greenberg, 1998) have made speculations about some of the components or processes that may be involved in such a network. Subsequent evidence from both functional neuroimaging and lesion studies will be required to develop a more sophisticated model of this hypothesized memory disorder.

Four patients demonstrated a purely semantic FRA. These cases are distinct from other, more general losses of knowledge (e.g., semantic dementia, visual agnosia) that impair the overall ability to neurally represent and become aware of factual information. These latter syndromes disrupt both the retrieval of previously learned semantic material and the ability to elaboratively rehearse and encode novel semantic information. All four patients had sustained lesions in the left lateral neocortex, in the parietal or the temporal areas. It will be difficult to draw firm conclusions about this syndrome of semantic FRA until additional patients are identified.

In two other clusters of patients with FRA, structural neuroimaging failed to discover the presence of anatomical injuries. These cases typically presented either a pure episodic deficit or an equivalent loss of both episodic and semantic memory, often with a temporal gradient. Although it is impossible to completely rule out psychogenic factors for these patients, we are in agreement with De Renzi et al. (1997) that, in the absence of factors that would be suggestive of psychological origin, such a label should be used sparingly. Instead, it may be more reasonable to believe that FRA results either from microscopic injuries, undetectable by conventional neuroimaging techniques, or from functional changes in neural communication following minor trauma.

A coexisting possibility is that FRA in these cases may involve a disruption in neural timing. If it is the case that complex retrieval requires synchronous, time-locked ac- tivity from multiple, distributed brain areas (Damasio, 1989), retrograde amnesia may reflect a failure of communication, rather than a structural problem. This possibility is especially likely for those cases in which the FRA was temporary and followed a relatively minor closedhead injury (Klein et al., 1996; Stracciari et al., 1994).

The points raised in this article have highlighted a number of areas for future research. There are several important questions about FRA that remain unanswered. For example, why do lesions in the temporal poles sometimes produce a profound episodic FRA and at other times lead to a much milder memory disorder? What is the connection between the temporal poles and more posterior visual areas, and why can injuries to these two areas produce such similar profiles on tests of retrograde memory? What is the status of pure semantic FRA-should it be considered as a special category of amnesia, as a disorder of knowledge representation, or both? How should one interpret the numerous case studies in which patients with nonremarkable structural neuroimages show retrograde losses of episodic memory or of both episodic and semantic memory? What is the relation between episodic and semantic retrieval, given that there are 16 documented cases demonstrating a complete loss of retrograde episodic memory, along with a significant, yet incomplete, loss of retrograde semantic memory? Progress on these and other issues will only come about through future empirical, methodological, and theoretical advances.

In conclusion, we conducted a literature review to summarize the various published case reports of FRA, especially as they relate to the episodic-semantic distinction. The distinction has been a useful organizing tool, because the majority of cases of FRA differentially impact the two varieties of memory and also because the classification has allowed a number of patterns to emerge that might not have been noticeable otherwise. We share the recent conclusions of Kapur (1999), who stressed that more attention should be paid to the syndrome of retrograde amnesia and also that there should be more communication between the various approaches that can be applied to the study of remote memory, such as structural and functional neuroimaging, lesion studies, and cognitive experiments with healthy adults. Ultimately, greater knowledge about FRA will surely be a powerful contribution toward the understanding of the neurocognitive processes in memory.

\section{REFERENCES}

Brown, J. W., \& СновоR, K. L. (1995). Severe retrograde amnesia. Aphasiology, 9, 163-170.

Calabrese, P., Markowitsch, H. J., Durwen, H. F., Widlitzek, H., Haupts, M., Holinka, B., \& Gehlen, W. (1996). Right temporofrontal cortex as critical locus for ecphory of old episodic memories. Journal of Neurology, Neurosurgery, \& Psychiatry, 61, 304-310.

Carlesimo, G. A., Sabbadini, M., Loasses, A., \& Caltagirone, C. (1998). Analysis of the memory impairment in a post-encephalitic patient with focal retrograde amnesia. Cortex, 34, 449-460.

Conway, M. A., \& Pleydell-Pearce, C. W. (2000). The construction 
of autobiographical memories in the self-memory system. Psychological Review, 107, 261-288.

Crovitz, H. F., \& Quina-Holland, K. (1976). Proportion of episodic memories from early childhood by years of age. Bulletin of the Psychonomic Society, 7, 61-62.

Crovitz, H. F., \& Schiffman, H. (1974). Frequency of episodic memories as a function of their age. Bulletin of the Psychonomic Society, 4, 517-518.

Dalla Barba, G., Parlato, V., Jobert, A., Samson, Y., \& Pappata, S. (1998). Cortical networks implicated in semantic and episodic memory: Common or unique? Cortex, 34, 547-561.

Damasio, A. R. (1989). Time-locked multiregional retroactivation: A systems-level proposal for the neural substrates of recall and recognition. Cortex, 33, 25-62.

Damasio, A. R., Eslinger, P. J., Damasio, H., Hoesen, G. V. V., \& Cornell, S. (1985). Multimodal amnesic syndrome following bilateral temporal and basal forebrain damage. Archives of Neurology, 42, 252-259.

De Renzi, E., Liotti, M., \& Nichelli, P. (1987). Semantic amnesia with a preservation of autobiographical memory: A case report. Cortex, 23, 575-597.

De Renzi, E., \& Lucchelli, F. (1993). Dense retrograde amnesia, intact learning capability and abnormal forgetting rate: A consolidation deficit. Cortex, 29, 449-466.

De Renzi, E., Lucchelli,F., Muggia, S., \& Spinnler,H. (1995).Persistent retrograde amnesia following a minor trauma. Cortex, $\mathbf{3 1}$, 531-542.

De Renzi, E., Lucchelli, F., Muggia, S., \& Spinnler, H. (1997). Is memory loss without anatomical damage tantamount to a psychogenic deficit? The case of pure retrograde amnesia. Neuropsychologia, 35, 781-794.

Evans, J. J., Breen, E. K., Antoun, N., \& Hodges, J. R. (1996). Focal retrograde amnesia for autobiographical events following cerebral vasculitis: A connectionist account. Neurocase, 2, 1-11.

Fink, G. R., Markowitsch, H. J., Reinkemeier, M., Bruckbaner, T., Kessler, J., \& HeIss, W. (1996). Cerebral representations of one's own past: Neural networks involved in autobiographical memory. Journal of Neuroscience, 18, 4275-4282.

Fuji, T., Yamadori, A., Endo, K., Suzuki, K., \& Fukatsu, R. (1999). Disproportionate retrog rade amnesia in a patient with herpes simplex encephalitis. Cortex, 35, 599-614.

Galton, F. (1879). Psychometric experiments. Brain, 2, 148-162.

GLENBERG, A. (1997). What memory is for. Behavioral \& Brain Sciences, 20, 1-19.

Goldberg, E., Antin, S. P., Bilder, R. M., Gerstmann, L. J., Hughes, J. E. O., \& MatTis, S. (1981, September 18). Retrograde amnesia: Possible role of mesencephalic reticular formation in long-term memory. Science, 213, 1392-1394.

Grossi, D., Trojano, L., Grasso, A., \& Orsini, A. (1988). Selective "semantic amnesia" after closed-head injury: A case report. Cortex, 24, 457-464.

Hodges, J. R., \& McCARthy, R. A. (1993). Autobiographical amnesia resulting from bilateral paramedian thalamic infarction. Brain, 116, 921-940.

Hokkanen, L., Launes, J., Vataja, R, Valanne, L., \& Iivanainen, M. (1995). Isolated retrograde amnesia for autobiographical material associated with acute left temporal lobe encephalitis. PsychologicalMedicine, 25, 203-208.

Hunkin, N. M., Parkin, A. J., Bradley, V. A., Burrows, E. H., AlDrich, F. K., JANSARI, A., \& BURdON-CoOPER, C. (1995). Focal retrograde amnesia following closed head injury: A case study and theoretical account. Neuropsychologia, 33, 509-523.

KAPUR, N. (1999). Syndromes of retrograde amnesia: A conceptual and empirical synthesis. Psychological Bulletin, 125, 800-825.

Kapur, N., Ellison, D., Parkin, A. J., Hunkin, N. M., Burrows, E. H., SAmpson, S. A., \& Morrison, E. A. (1994). Bilateral temporal lobe pathology with sparing of medial temporal lobe structures: Lesion profile and pattern of memory disorder. Neuropsychologia, 32, 23-38.

Kapur, N., Ellison, D., Smith, M. P., McLellan, D. L., \& Burrows, E. H. (1992). Focal retrograde amnesia following bilateral temporal lobe pathology. Brain, 115, 73-85.
Kapur, N., Scholey, K., Moore, E., Barker, S., Brice, J., Thompson, S., Shiel, A., Carn, R., Авbott, P., \& Fleming, J. (1996). Long-term retention deficits in two cases of disproportionate retrograde amnesia. Journal of Cognitive Neuroscience, 8, 416-434.

Kapur, N., Young, A., Bateman, D., \& Kennedy, P. (1989). Focal retrograde amnesia: A long term clinical and neuropsychological followup. Cortex, 25, 387-402.

Kinlstrom, J. F., \& Schacter, D. L. (1995). Functional disorders of autobiographical memory. In A. D. Baddeley, B. Wilson, \& F. Watts (Eds.), Handbook of memory disorders (pp. 337-364). Chichester, U.K.: Wiley.

Klein, S. B., Loftus, J., \& Kinlstrom, J. F. (1996). Self-knowledge of an amnesiac patient: Toward a neuropsychology of personality and social psychology. Journal of Experimental Psychology: General, 125, 250-260.

Kopelman, M. D. (1987). Amnesia: Organic and psychogenic. British Journal of Psychiatry, 150, 428-442.

Kopelman, M. D., Stanhope, N., \& Kingsley, D. (1999). Retrograde amnesia in patients with diencephalic, temporal lobe or frontal lesions. Neuropsychologia, 37, 939-958.

Kopelman, M. D., Wilson, B. A., \& Baddeley, A. D. (1990). The Autobiographical Memory Interview. Bury St. Edmonds, U.K.: Thames Valley Test Company.

Kroll, N. E., Markowitsch, H. J., Knight, R. T., \& von Cramon, D. Y. (1997). Retrieval of old memories: The temporofrontal hypothesis. Brain, 120, 1377-1399.

Levine, B., Black, S. E., Cabeza, R., Sinden, M., McIntosh, A. R. Toth, J. P., Tulving, E. \& Stuss, D. T. (1998). Episodic memory and the self in a case of isolated retrograde amnesia. Brain, 121, 1951-1973.

Lucchelli, F., Muggia, S., \& Spinnler, H. (1995). The "Petites Madeleines" phenomenon in two amnesiac patients: Sudden recovery of forgotten memories. Brain, 118, 167-183.

Maguire, E. A. \& Mummery, C. J. (1999). Differential modulation of a common memory retrieval network revealed by positron emission tomography. Hippocampus, 9, 54-61.

Maravita, A., Spadoni, M., Mazzucchi, A., \& Parma, M. (1995). A new case of retrograde amnesia with abnormal forgetting rate. Cortex, 31, 653-667.

Markowitsch, H. J., Calabrese, P., Haupts, M., Durwen, H. F., Liess, J., \& Gehlen, W. (1993). Searching for the anatomical basis of retrograde amnesia. Journal of Clinical \& Experimental Neuropsychology, 15, 947-967.

Markowitsch, H. J., Calabrese, P., Neufeld, H., Gehlen, W., \& DurWEn, H. F. (1999). Retrograde amnesia for world knowledge and preserved memory for autobiographical events: A case report. Cortex, 35, 243-252.

Markowtisch, H. J., Emmans, D., Irle, E., Streicher, M., \& PreiLOWSKI, B. (1985). Cortical and subcortical afferent connections of the primate's temporal pole: A study of rhesus monkeys, squirrel monkeys, and marmosets. Journal of Comparative Neurology, 242, 425-458.

Mattioli, F., Grassi, F., Perani, D., Cappa, S. F., Miozzi, A. \& Fazio, F. (1996). Persistent posttraumatic retrograde amnesia: A neuropsychological and (18F)FDG PET study. Cortex, 32, 121-129.

McClelland, J. L., McNaughton, B. L., \& O’Reilly, R. C. (1995). Why are there complementary learning systems in the hippocampus and neocortex: Insights from the successes and failures of connectionist models of learning and memory. Psychological Review, 102, 419-457.

NADEL,L., \& Moscovitch, M. (1997). Memory consolidation, retrograde amnesia and the hippocampal complex. Current Opinion in Neurobiology, 7, 217-227.

Nyberg, L., Tulving, E., Habib, R., Nilsson, L. G., Kapur, S., Houle, S., Cabeza, R., \& McIntosh, A. R. (1995). Functional brain maps of retrieval mode and recovery of episodic information. NeuroReport, 7, 249-252.

O'Connor, M., Butters, N., Miliotis, P., Eslinger, P., \& Cermak, L. S. (1992). The dissociation of anterograde and retrograde amnesia in a patient with herpes encephalitis. Journal of Clinical \& Experimental Neuropsychology, 14, 159-178.

Ogden, J. A. (1993). Visual object agnosia, prosopagnosia, achromatopsia, loss of visual imagery, and autobiographical amnesia follow- 
ing recovery from cortical blindness: Case M.H. Neuropsychologia, 31, 571-589.

Pandya, D. N., \& Barnes, C. L. (1987). Architecture and connections of the frontal lobe. In E. Perecman (Ed.), The frontal lobes revisited (pp. 159-188). Hillsdale, NJ: Erlbaum.

ReinVAng, I., \& GJERSTAD, L. (1998). Focal retrograde amnesia associated with vascular headache. Neuropsychologia, 36, 1335-1341.

Roman-Campos, G., Poser, C. M., \& Wood, F. B. (1980). Persistent retrograde amnesia after transient global amnesia. Cortex, 16, 509-518.

Rubin, D. C., \& GreenberG, D. L. (1998). Visual memory-deficit amnesia: A distinct amnesic presentation and etiology. Proceedings of the National Academy of Sciences, 95, 5413-5416.

Schacter, D. L., Harbluk, J. L., \& McLachlan, D. R. (1984). Retrieval without recollection: An experimental analysis of source amnesia. Journal of Verbal Learning \& Verbal Behavior, 23, 593-611.

Snowden, J., Neary, D., \& Mann, D. (1996). Frontotemporal lobar degeneration: Frontotemporal dementia, progressive aphasia, semantic dementia. London: Churchill Livingstone.

Stracciari, A., Ghidoni, E., Guarino, M., Poletti, M., \& PazzaGLIA, P. (1994). Post traumatic retrograde amnesia with selective impairment of autobiographical memory. Cortex, 30, 459-468.

Stuss, D. T., \& Guzman, D. A. (1988). Severe remote memory loss with minimal anterograde amnesia: A clinical note. Brain \& Cognition, 8, 21-30.

Tanaka, K., Miyazawa, Y., Hashimoto, R., Nakano, I., \& ObaYASHI, T. (1999). Postencephalitic focal retrograde amnesia after bilateral anterior temporal lobe damage. Neurology, 53, 344-350.

Tulving, E. (1983). Elements of episodic memory. New York: Oxford University Press.
Tulving, E. (1984). Precis of Elements of episodic memory. Behavioral \& Brain Sciences, 7, 223-268.

Tulving, E., Kapur, S., Craik, F. I. M., Moscovitch, M., \& Houle, S. (1994). Hemispheric encoding/retrieval asymmetry in episodic memory: Positron emission tomography findings. Proceedings of the $\mathrm{Na}$ tional Academy of Sciences, 91, 2016-2020.

Tulving, E., \& Markowitsch, H. J. (1998). Episodic and declarative memory: Role of the hippocampus. Hippocampus, 8, 198-204.

Viskontas, I. V., McAndrews, M. P., \& Moscovitch, M. (2000). Remote episodic memory deficits in patients with unilateral temporal lobe epilepsy and excisions. Journal of Neuroscience, 20, 5853-5857.

Warrington, E. K., \& Shallice, T. (1984). Category specific impairments. Brain, 107, 829-854.

Wheeler, M. A., Stuss, D. T., \& Tulving, E. (1997). Toward a theory of episodic memory: The frontal lobes and autonoetic consciousness. Psychological Bulletin, 121, 331-354.

Williams, M., \& Smith, H. V. (1954). Mental disturbances in tuberculosis meningitis. Journal of Neurology, Neurosurgery, \& Psychiatry, 17, 173-182.

Yasuda, K., Watanabe, D., \& ONo, Y. (1997). Dissociation between semantic and autobiographicmemory: A case report. Cortex, 33, 623-638.

YonedA, Y., YAmadori, A., Mori, E., \& YAmashita, H. (1992). Isolated prolonged retrograde amnesia. European Neurology, 32, 340-342.

(Manuscript received July 5, 2000; revision accepted for publication January 12, 2001.) 